\title{
A case report of prucalopride in pediatric gastroparesis: a novel therapy
}

\author{
Diana P. Escobar-Serna ${ }^{a, b}$ (D), Fernando J. Peralta-Palmezano ${ }^{(\mathbb{D}}$, Juan J. Peralta-Palmezano ${ }^{a, b}$ (D)
}

\begin{abstract}
Prucalopride has been used in adults with gastroparesis, accelerating gastric emptying. There are no studies with this drug in gastroparetic children. An 8-year-old boy is presented who consulted for a month of postprandial symptoms, with a diagnosis of gastroparesis by gastric emptying scintigraphy. He did not improve with metoclopramide, domperidone, erythromycin, and esomeprazole. He received prucalopride for two periods (for 178 and 376 days) at doses: $0.03-0.04 \mathrm{mg}$ / $\mathrm{kg} /$ day, presenting improvement in the follow-up with the cardinal gastroparesis symptom index and gastric emptying scintigraphy. Due to the good response, prucalopride may be a therapeutic option in pediatric gastroparesis.

Key words: gastroparesis, receptors serotonin, serotonin $5-\mathrm{HT}_{4}$ receptor agonists, gastric emptying, radionuclide imaging.
\end{abstract}

http: / / dx.doi.org/10.5546/ aap.2022.eng.e98

To cite: Escobar-Serna DP, Peralta-Palmezano FJ, Peralta-Palmezano JJ. A case report of prucalopride in pediatric gastroparesis: a novel therapy. Arch Argent Pediatr 2022;120(2):e98-e101.

\section{INTRODUCTION}

Gastroparesis is a delay in gastric emptying without a mechanical obstruction. It presents with: vomits, abdominal pain, nausea, early satiety, and abdominal distention. ${ }^{1,2}$ Its main causes are: idiopathic, drugs, postsurgical, postviral, diabetic. ${ }^{2}$ Drugs that act on 5-hydroxytryptamine (5-HT) receptors are alternatives for treating gastroparesis. Two no

a. Department of Pediatrics, Universidad Nacional de Colombia, Bogotá, Colombia.

b. Department of Pediatrics, HOMI-Fundación Hospital Pediátrico la Misericordia, Bogotá, Colombia.

c. Department of Gynecology \& Obstetrics, Universidad de Antioquia, Medellín, Colombia.

E-mail address:

Juan J. Peralta-Palmezano: jjperaltap@unal.edu.co

Funding: None.

Conflict of interest: None.

Received: 6-19-2021

Accepted: 7-9-2021 selective $5-\mathrm{HT}_{4}$ agonists, cisaprida and tegaserod, accelerate gastric emptying. These are not recommended due to QT interval prolongation and myocardial ischemia, while selective $5-\mathrm{HT}_{4}$ receptor agonists have not reported these adverse effects. ${ }^{3}$ Prucalopride is a benzofuran derivative and a specific $5-\mathrm{HT}_{4}$ receptor agonist. In children it has a fast oral absorption, a peak plasma concentration reached two hours after ingestion, a fast distribution, a plasma protein binding of $28.6 \%$, and an elimination half-life of 19 hours. ${ }^{4}$ In healthy and constipated adults, prucalopride accelerates gastric emptying and small bowel transit. 5,6 It proved to be a safe drug in children and adults, with mild and transient adverse events (abdominal pain, headache, fecal incontinence, nausea, flatulence). ${ }^{4-6}$ When administered for four weeks in adults with gastroparesis, it shortened solid gastric emptying times and improved symptom severity, with few adverse events. ${ }^{7}$ There are no studies with this drug for children with gastroparesis.

The gastroparesis cardinal symptom index (GCSI) may be helpful in monitoring response to treatment, ${ }^{8}$ with a good understanding of most terms by children. ${ }^{9}$ It evaluates three groups of symptoms: nausea/vomiting, postprandial fullness/early satiety, and bloating. The score is calculated as the average of all subscale scores (each subscale score is calculated by averaging the items within it); scores range from 0 (none) to 5 (very severe). ${ }^{8}$

We report the case of a child with gastroparesis treated with prucalopride, with prolonged followup with gastric emptying scintigraphy and the GCSI.

\section{CASE REPORT}

An 8-year-old boy consulted for a month of abdominal pain in epigastrium and mesogastrium, early satiety, postprandial distention, regurgitation, constipation, occasional vomits, and weight loss. He had a history of functional constipation since one year-old, occasionally medicated with polyethylene glycol without electrolytes. Hemogram, electrolytes, and $\mathrm{C}$-reactive protein were normal. Abdominal X-ray 
showed signs of constipation. He was hospitalized for treatment with intravenous fluids, analgesia, esomeprazole, and polyethylene glycol without electrolytes. Vomits improved, but persisted with early satiety, abdominal distension, postprandial nausea, and constipation. Solid and liquid gastric emptying scintigraphy diagnosed gastroparesis (results in Table 1). We assessed the cause of gastroparesis with: upper gastrointestinal series, esophagogastroduodenoscopy, blood glucose, thyroid function, abdominal ultrasound, serum immunoglobulins, transaminases, bilirubin, blood urea nitrogen, creatinine, electrolytes, triglycerides, cholesterol, immunoglobulin A anti-tissue transglutaminase antibody, vitamin E, vitamin $\mathrm{D}_{3^{\prime}}$ homocysteine, ammonium, lactate/ pyruvate, audiometry, echocardiogram, electrocardiogram; without alterations. Stomach biopsy showed chronic non-atrophic gastritis, without alterations in esophagus and duodenum.
The patient received for gastroparesis: domperidone, erythromycin and metoclopramide, changing the medications because there was no improvement in symptoms. For gastritis he received esomeprazole. For constipation he received polyethylene glycol without electrolytes and sodium picosulfate was added due to persistence of stools Bristol type 1 and 2. Table 2 describes the doses and treatment time.

During hospitalization, the patient persisted with hyporexia, with a loss of $2.5 \mathrm{~kg}$ after 40 days of hospitalization, requiring parenteral nutrition for 20 days; nutritional follow-up is described in Table 3. On 42nd hospitalization day, considering there was no improvement in the symptoms (GCSI of 2.7), and with the consent of the parents, we started prucalopride (dose: $0.04 \mathrm{mg} / \mathrm{kg} /$ day), suspending the other laxatives and prokinetics. On day 10 with prucalopride we performed a hemogram, electrolytes, transaminase, bilirubin,

TABLE 1. Liquid and Solid Gastric Emptying Scintigraphy Results and GCSI Scores

\begin{tabular}{|c|c|c|c|c|c|c|c|c|c|}
\hline & $\begin{array}{c}10^{\text {th }} \text { day of } \\
\text { hospital } \\
\text { stay }\end{array}$ & Day 1 & Day 88 & Day 178 & $\begin{array}{l}\text { 30th day } \\
\text { without } \\
\text { treatment }\end{array}$ & Day 1 & Day 62 & Day 376 & $\begin{array}{c}77 \text { th day } \\
\text { without } \\
\text { treatment }\end{array}$ \\
\hline Prucalopride & & \multicolumn{3}{|c|}{ First treatment period } & \multicolumn{5}{|c|}{ Second treatment period } \\
\hline $\begin{array}{l}\text { Solid gastric } \\
\text { emptying } \\
\text { scintigraphy }\end{array}$ & $\begin{array}{c}3 \mathrm{~h}: 37 \% \\
4 \mathrm{~h}: 6 \% \\
\mathrm{t}_{1 / 2}: 154\end{array}$ & & $\begin{array}{l}1 \text { h: } 83 \% \\
2 \text { h: } 50 \% \\
3 \text { h: } 33 \% \\
4 \text { h: } 16 \% \\
t_{1 / 2}: 131\end{array}$ & & $\begin{array}{l}1 \text { h: } 93 \% \\
2 \text { h: } 83 \% \\
3 \text { h: } 63 \% \\
4 \text { h: } 43 \% \\
t_{1 / 2}: 241\end{array}$ & & $\begin{array}{l}1 \text { h: } 76 \% \\
2 \text { h: } 62 \% \\
3 \text { h: } 38 \% \\
4 \text { h: } 26 \% \\
t_{1 / 2}: 167\end{array}$ & & $\begin{array}{c}1 \text { h: } 71 \% \\
2 \text { h: } 47 \% \\
3 \text { h: } 24 \% \\
4 \text { h: } 0 \% \\
t_{1 / 2}: 115\end{array}$ \\
\hline $\begin{array}{l}\text { Liquid gastric } \\
\text { emptying } \\
\text { scintigraphy }\end{array}$ & $\mathrm{t}_{1 / 2}: 78 \mathrm{~min}$ & & $\mathrm{t}_{1 / 2}: 74 \mathrm{~min}$ & & $\mathrm{t}_{1 / 2}: 62 \mathrm{~min}$ & & $t_{1 / 2}: 60 \mathrm{~min}$ & & $\mathrm{t}_{1 / 2}: 29 \mathrm{~min}$ \\
\hline GCSI & 2.7 & 2.7 & 0.17 & 0 & 0 & 3.2 & 1.75 & 0 & 0 \\
\hline
\end{tabular}

GCSI: gastroparesis cardinal symptom index, scores range from 0 (none or absent) to 5 (very severe).

$t_{1 / 2}$ : average time of gastric emptying measured in minutes. Normal value of $t_{1 / 2}$ for solids: 132 minutes.

aRadiolabel retention percentages. normal values: $1 \mathrm{~h}<90 \%, 2 \mathrm{~h}<60 \%, 3 \mathrm{~h}<30 \%, 4 \mathrm{~h}<10 \%$.

TABLE 2. Dose and treatment time with the medications received prior to the start of prucalopride.

\begin{tabular}{|c|c|c|c|c|c|c|c|c|c|}
\hline & \multicolumn{9}{|c|}{ Hospitalization days } \\
\hline & 1 & 13 & 19 & 20 & 21 & 25 & 28 & 34 & 43 \\
\hline \multicolumn{10}{|l|}{ Domperidone (dose: $0.9 \mathrm{mg} / \mathrm{kg} /$ day, three times a day) } \\
\hline \multicolumn{10}{|l|}{ Erythromycin (dose: 15 mg / kg/day, three times a day) } \\
\hline \multicolumn{10}{|l|}{ Metoclopramide (dose: $0.6 \mathrm{mg} / \mathrm{kg} /$ day, three times a day) } \\
\hline \multicolumn{10}{|l|}{ Esomeprazole (dose: $1 \mathrm{mg} / \mathrm{kg}$ / day) } \\
\hline \multicolumn{10}{|l|}{ Polyethylene glycol without electrolytes (dose: 1 g/kg/day) } \\
\hline Sodium picosulfate (dose: $6 \mathrm{mg}$ / day) & & & & & & & & & \\
\hline
\end{tabular}


blood urea nitrogen, creatinine, triglycerides, total cholesterol and electrocardiogram; with normal results. At day 18 of prucalopride his symptoms improved with a GCSI of 0.75 . On day 20 he presented a colicky abdominal pain, with radiography and abdominal ultrasound without alterations. Due to persistent pain, we reduced prucalopride dose to $0.03 \mathrm{mg} / \mathrm{kg} /$ day. Abdominal pain improved after 5 days of dose reduction (GCSI de 0.4). We sent him home with prucalopride and esomeprazole.

In the outpatient follow-up, at 71 days with prucalopride we performed a hemogram, transaminase, albumin, bilirubin, and electrolytes; with normal results. On day 88 we performed a second gastric emptying scintigraphy (Table 1). On day 178 and with a GCSI of 0 , prucalopride and esomeprazole were discontinued. One month after prucalopride suspension we performed a third scintigraphy (Table 1). The patient remained asymptomatic for 56 days with recurrence of abdominal pain, constipation, regurgitation, nausea, vomiting, and a GCSI of 3.2. We started a second period with prucalopride (dose: $0.03 \mathrm{mg} / \mathrm{kg} /$ day) and after 16 days of treatment, he had a GCSI of 2.2. On day 43, due to persistence of postprandial symptoms, we increased prucalopride dose to $0.04 \mathrm{mg} / \mathrm{kg} /$ day. On day 62 , we performed a fourth scintigraphy (Table 1). On day 82, he persisted with a GCSI of 1.75 , so esomeprazole was discontinued. On days 108 and 152 GCSI improved, with 0.75 and 0.3 respectively. In total, he received 376 days of prucalopride (dose: $0.04 \mathrm{mg} / \mathrm{kg} /$ day), with a GCSI of 0 , with daily stools, weight gain, and normal electrocardiogram. At 77 days of follow-up without prucalopride, he remained asymptomatic, improving scintigraphy (Table 1).

\section{DISCUSSION}

We present a child with gastroparesis who did not improve with metoclopramide, domperidone, erythromycin, and esomeprazole. This forced us to consider prucalopride, used in children with constipation; ${ }^{4}$ but it also accelerates gastric emptying, ${ }^{5-7}$ improves gastric accommodation, ${ }^{10}$ increases sensitivity to gastric distention ${ }^{10}$ and accelerates intestinal transit., ${ }^{4,6}$

Prucalopride mimics the 5-TH agonist effect at the $5-\mathrm{HT}_{4}$ receptor. When stimulating $5-\mathrm{HT}_{4}$ receptors located in the myenteric plexus, acetylcholine is released, producing muscle contraction. ${ }^{11}$ While stimulating those located in smooth muscle, cyclic AMP is generated, inhibiting muscle contractions. ${ }^{12}$ In stomach antrum and body, 5- $\mathrm{HT}_{4}$ receptors are located in the myenteric plexus; while in the fundus they are distributed in the muscle..$^{13}$ In the stomach, antrum determines solid emptying ${ }^{14}$ and fundus, liquids emptying. ${ }^{15}$ The patient had delayed solid and liquid gastric emptying. Success with prucalopride could also be due to an improvement in gastric accommodation, ${ }^{10}$ which is a reduction in gastric tone with an increase in fundic volume in response to food intake.

In the first prucalopride period, the GCSI improved at 18 days, a time similar to that reported in another study. ${ }^{7}$ In the second period, response time was longer, 108 days. This difference in response time may be explained by his nutritional compromise at the beginning of the second prucalopride period or an adverse reaction to esomeprazole. Increases in gastrin, secondary to proton pump inhibitors, decrease the amplitude of gastric contractions, causing a delay in gastric emptying. ${ }^{15}$ Twenty-five days after suspending esomeprazole, GCSI improved.

Table 3. Nutritional follow-up.

\begin{tabular}{|c|c|c|c|c|c|c|c|}
\hline & \multicolumn{3}{|c|}{ Hospitalization days } & \multirow{2}{*}{$\begin{array}{c}\begin{array}{c}\text { First prucalopride } \\
\text { period }\end{array} \\
\text { Day } 124\end{array}$} & \multicolumn{3}{|c|}{ Second prucalopride period } \\
\hline & Day 1 & Day 19 & Day 40 & & Day 65 & Day 152 & Day 376 \\
\hline Weight $(\mathrm{kg})$ & 20 & 19.5 & 17.5 & 20 & 20 & 21 & 26 \\
\hline Height $(\mathrm{cm})$ & 119 & 119 & 119 & 120 & 121.5 & 121.5 & 122 \\
\hline $\operatorname{BMI}\left(\mathrm{kg} / \mathrm{m}^{2}\right)$ & 14.1 & 13.8 & 12.3 & 13.9 & 13.5 & 14.2 & 17.5 \\
\hline BMI/Age ${ }^{\mathrm{a}}$ & -1.37 & -1.68 & -3.56 & -1.65 & -2.14 & -1.51 & 0.38 \\
\hline Height / Age ${ }^{a}$ & -1.87 & -1.88 & -1.93 & -2.05 & -2.05 & -2.34 & -2.65 \\
\hline
\end{tabular}

BMI: Body Mass Index

aStandard deviations, according to the World Health Organization growth charts 
Proton pump inhibitors are used in up to $79 \%$ of children with gastroparesis, ${ }^{1}$ so discontinuation is considered when there is no adequate response with prokinetics.

The patient was followed up with GCSI and scintigraphy. Although a study with children showed that GCSI was not associated with delays in gastric emptying, it had the limitations of not having used the Rome criteria to rule out functional dyspepsia and a small sample. ${ }^{9}$ The first scintigraphy shows an association with GCSI. When performing the second scintigraphy, despite improvement of the GCSI, there was nutritional compromise, which could have influenced the results. When the first period with prucalopride was suspended, there was deterioration in the third scintigraphy, a recurrence of symptoms, and a more delayed response to treatment. The treatment time is not clear and it took more than a year with prucalopride to show improvements in the GCSI and normal scintigraphy.

This patient tolerated prucalopride well, only presenting abdominal pain that improved with the decrease in dose, without other adverse effects. We believe that prucalopride could be an option in the management of children with idiopathic gastroparesis and studies in children are needed to evaluate its safety and effectiveness.

\section{REFERENCES}

1. Rodríguez L, Irani K, Jiang H, Goldstein AM. Clinical presentation, response to therapy, and outcome of gastroparesis in children. J Pediatr Gastroenterol Nutr. 2012; 55(2):185-90.

2. Waseem S, Islam S, Kahn G, Moshiree B, Talley N.Spectrum of gastroparesis in children. J Pediatr Gastroenterol Nutr. 2012; 55(2):166-72.

3. Tack J, Camilleri M, Chang L, Chey WD, et al. Systematic review: cardiovascular safety profile of 5-HT(4) agonists developed for gastrointestinal disorders. Aliment Pharmacol Ther. 2012; 35(7):745-67.

4. Winter HS, Di Lorenzo C, Benninga MA, Gilger MA, et al. Oral prucalopride in children with functional constipation. J Pediatr Gastroenterol Nutr. 2013; 57(2):197-203.

5. Kessing BF, Smout AJ, Bennink RJ, Kraaijpoel N, et al. Prucalopride decreases esophageal acid exposure and accelerates gastric emptying in healthy subjects. Neurogastroenterol Motil. 2014; 26(8):1079-86.

6. Bouras EP, Camilleri M, Burton DD, Thomforde G, et al. Prucalopride accelerates gastrointestinal and colonic transit in patients with constipation without a rectal evacuation disorder. Gastroenterology. 2001; 120(2):354-60.

7. Carbone F, Van den Houte K, Clevers E, Andrews CN, et al. Prucalopride in Gastroparesis: A Randomized PlaceboControlled Crossover Study. Am J Gastroenterol. 2019; 114(8):1265-74.

8. Revicki DA, Rentz AM, Dubois D, Kahrilas P, et al. Development and validation of a patient-assessed gastroparesis symptom severity measure:The Gastroparesis Cardinal Symptom Index. Aliment Pharmacol Ther. 2003; 18(1):141-50

9. Jericho H, Adams P, Zhang G, Rychlik K, Saps M. Nausea predicts delayed gastric emptying in children. J Pediatr. 2014; 164(1):89-92.

10. Carbone F, Tack J. OP006. The effect of prucalopride on gastric accommodation in healthy volunteers. Neurogastroenterol Motil. 2014; 26(Suppl. 1):3-4.

11. Kilbinger H, Wolf D. Effects of 5-HT4 receptor stimulation on basal and electrically evoked release of acetylcholine from guinea-pig myenteric plexus. Naunyn Schmiedebergs Arch Pharmacol. 1992; 345(3):270-5.

12. McLean PG, Coupar IM. Stimulation of cyclic AMP formation in the circular smooth muscle of human colon by activation of 5-HT4-like receptors. Br J Pharmacol. 1996; 117(2):238-9.

13. Takada K, Sakurai-Yamashita Y, Yamashita K, Kaibara M, et al. Regional difference in correlation of 5-HT4 receptor distribution with cholinergic transmission in the guinea pig stomach. Eur J Pharmacol. 1999; 374(3):489-94.

14. Camilleri M, Malagelada JR, Brown ML, Becker G, Zinsmeister AR. Relation between antral motility and gastric emptying of solids and liquids in humans. Am J Physiol. 1985; 249(5 Pt 1):G580-5.

15. Dozois RR, Kelly KA. Effect of a gastrin pentapeptide on canine gastric emptying of liquids. Am J Physiol. 1971; 221(1):113-7. 